Research Article

\title{
Genetic Diversity and Virulence Factors of $S$. aureus Isolated from Food, Humans, and Animals
}

\author{
Roberto Adame-Gómez, ${ }^{1}$ Natividad Castro-Alarcón, ${ }^{2}$ Amalia Vences-Velázquez, ${ }^{3}$ \\ Jeiry Toribio-Jiménez, ${ }^{4}$ Abigail Pérez-Valdespino, ${ }^{5}$ Marco- Antonio Leyva-Vázquez, ${ }^{6}$ \\ and Arturo Ramírez-Peralta ${ }^{1}{ }^{1}$ \\ ${ }^{1}$ Laboratorio de Investigación en Patometabolismo Microbiano, Universidad Autónoma de Guerrero, Chilpancingo, \\ Guerrero, Mexico \\ ${ }^{2}$ Laboratorio de Investigación en Microbiología, Universidad Autónoma de Guerrero, Chilpancingo, Guerrero, Mexico \\ ${ }^{3}$ Laboratorio de Investigación en Inmunobiologia y Diagnóstico Molecular, Universidad Autónoma de Guerrero, \\ Chilpancingo, Guerrero, Mexico \\ ${ }^{4}$ Laboratorio de Investigación en Microbiología Molecular y Biotecnología Ambiental, Universidad Autónoma de Guerrero, \\ Chilpancingo, Guerrero, Mexico \\ ${ }^{5}$ Laboratorio de Ingenieria Genética, Departamento de Bioquímica, Escuela Nacional de Ciencias Biológicas, \\ Instituto Politécnico Nacional, Ciudad de México, Mexico \\ ${ }^{6}$ Laboratorio de Investigación en Biomedicina Molecular, Universidad Autónoma de Guerrero, Chilpancingo, Guerrero, Mexico
}

Correspondence should be addressed to Arturo Ramírez-Peralta; ramirezperaltauagro@gmail.com

Received 27 March 2020; Accepted 25 May 2020; Published 27 August 2020

Academic Editor: Joseph Falkinham

Copyright (C) 2020 Roberto Adame-Gómez et al. This is an open access article distributed under the Creative Commons Attribution License, which permits unrestricted use, distribution, and reproduction in any medium, provided the original work is properly cited.

Staphylococcus aureus is a commensal bacterium in humans and animals able to adapt to multiple environments. The aim of this study was to compare the genetic diversity and virulence profiles of strains of S. aureus isolated from food ( 29 strains), humans (43 strains), and animals (8 strains). 80 lipase-producing strains belonging to a biobank of 360 isolates, identified phenotypically as $S$. aureus, were selected. Confirmation of the species was made by amplifying the $s p A$ gene and $80 \%(64 / 80)$ of the strains were confirmed within this species. The virulence profile of each of the isolates was determined by PCR. The seA gene coding for enterotoxin A was found in $53.1 \%$ of the strains, the $s a K$ gene, which codes for Staphylokinase, was amplified in $57.8 \%$ of the strains, and, finally, the $h l B$ gene coding for $\beta$-Hemolysin was amplified in $17.2 \%$. The profile of antimicrobial resistance was determined by the Kirby Bauer method showing that the strains from food presented greater resistance to erythromycin (40.7\%) and ciprofloxacin (18.5\%) while in strains isolated from humans were to erythromycin (48.4\%) and clindamycin (21.2\%). Also, in strains from animals, a high resistance to erythromycin was observed (75\%). The frequency of MRSA was $12.5 \%$ due to the presence of the mec gene and resistance to cefoxitin. Of the total strains, $68.7 \%$ were typed by PCR-RFLP of the coa gene using the AluI enzyme; derived from this restriction, 17 profiles were generated. Profile 4 ( $490 \mathrm{bp}, 300 \mathrm{bp}$ ) was the most frequent, containing a higher number of strains with a higher number of virulence factors and antimicrobial resistance, which is associated with greater adaptation to different environments. In this study, a wide genetic diversity of strains of $S$. aureus from different foods, humans, and animals was found. This demonstrates evolution, genetic versatility, and, therefore, the adaptation of this microorganism in different environments.

\section{Introduction}

Staphylococcus aureus is a commensal bacterium that is part of the microbiota of the skin and mucous membranes of humans and some animals. However, when the conditions in the host are adequate for the proliferation of the microorganism, it causes pathologies in humans such as pneumonia, endocarditis, osteomyelitis, impetigo, skin 
infections, and healthcare-associated infections (HAI) [1]; in animals, it is associated with infections in mammary glands [2], and, in the case of food, $S$. aureus produces a great diversity of enterotoxins that generate food poisoning in humans due to the consumption of these [3]; being a microorganism, it also affects the quality of foods, such as raw meat products [4] and milk and dairy products [5].

The successful colonization of $S$. aureus in multiple environments, different inanimate hosts, or matrices is possible due to the large number of virulence factors that this microorganism uses [6]. S. aureus produces a large number of enzymes that promote the virulence of this microorganism, including coagulase, staphylokinase, and $\beta$-lactamases [7]. Among the virulence factors that have an important role in pathogenicity are adhesins and surface proteins, such as protein $\mathrm{A}$, and, in the particular case of toxins, enterotoxins of $S$. aureus (SE) and $\beta$-Hemolysin (Hlb) [8].

S. aureus has the ability to control the expression of virulence factors according to the environmental conditions in which it is found through a global regulation system known as accessory regulatory gene (Agr) [8] and the sigma factor $(\sigma \mathrm{B})$ [9]. In addition to gene regulation, the adaptation of $S$. aureus in different microenvironments with different environmental, nutritional, and stress conditions could generate the acquisition of genes coding for virulence factors that allow its survival [10]. The mobilization of several genes that code for virulence factors in the same mobile genetic element has been observed; for example, in the bacteriophage $\beta \mathrm{C}-\varphi s$, the staphylokinase gene and the complement inhibitor protein are mobilized with enterotoxin genes and Panton- Valentine leucocidin[11]. Also, in the Staphylococcus aureus pathogenicity islands (SaPIs), this phenomenon has been observed, mobilizing two genes of enterotoxins along with the toxin gene of toxic shock syndrome (tsst-1) and the adhesion protein Bap [12]. Another example is the catabolic mobile element of arginine that is transported together with the methicillin resistance cassette (SCCmec) due to its proximity and which has been related to strains that have specific subtypes of SCCmec [1010]. Transfer of antibiotic resistance genes is common in Staphylococcal species [13]. Resistance against methicillin, lincosamides, macrolides, aminoglycosides, and a combination of these antibiotics has been frequently reported in staphylococci [14].

For this reason, it has been difficult to separate a group of $S$. aureus clones with certain virulence factors that generate disease from those clones that are only commensals. Therefore, molecular typing techniques, such as pulsed-field gel electrophoresis (PFGE) and multilocus sequencing typing (MLST) [15], have been designed, being the PFGE technique the gold standard for the typing of $S$. aureus. However, due to the high costs, other alternatives of molecular biology have been proposed, such as PCR-RFLPs of the coagulase gene (coa) or the protein A gene (spA) $[16,17]$, genes conserved in genus and species, respectively. In the case of typing by $s p A$, a $100 \%$ relationship was found with PFGE [18]. Currently, the restriction of these genes continues to be used to typify strains of $S$. aureus of different origins $[19,20]$. However, the rapid transformation of this bacterium generates the need for the study of virulence factors, which could provide information on their function in the dissemination and adaptation of the same clone of $S$. aureus in multiple environments, considering that most studies evaluate genetic diversity in a particular environment. Therefore, the objective of this study was to compare the genetic diversity and virulence factor profiles of strains of $S$. aureus from food, humans, and animals.

\section{Materials and Methods}

2.1. Strains. For this study, 80 strains previously identified at genus level were selected by primary isolation in Baird Parker agar, Gram stain, fermentation of mannitol and trehalose, coagulase, and positive catalase from a collection of 360 strains of $S$. aureus isolated from different sources (food, humans, and animals), which were stored at $-20^{\circ} \mathrm{C}$ in 20\% glycerol (Merck Millipore Cat\# 356352, Germany)/ brain heart infusion broth BHI (Oxoid, Cat\# CM1135, USA). The production of enterotoxin A had been previously determined by dot blot and methicillin resistance in 34 strains $[21,22]$. The lipase production was considered as a metabolic characteristic for the selection of the 80 strains for this study due to their participation in infections in humans and animals, as well as their survival and multiplication in contaminated foods [23]. Another important characteristic of this group of strains is that they were isolated from food, humans, and animals from the same city (Chilpancingo, southern Mexico) and nearby towns.

Strains were cultured in BHI broth and incubated for $24 \mathrm{~h}$ at $37^{\circ} \mathrm{C}$. The control strains used in this study were Staphylococcus aureus ATCC 29231 (sea), Staphylococcus aureus ATCC 14458 (seb), Staphylococcus aureus ATCC 19095 (sec), Staphylococcus ATCC 13563 (sed), Staphylococcus ATCC 27664 (see), and Staphylococcus aureus ATCC 25923 (coa, spa, hlB, and sak).

2.2. DNA Extraction. Total DNA were isolated from $1 \mathrm{~mL}$ of an $18 \mathrm{~h}$ broth culture from all the bacterial strains including ATCC strains. Cells were pelleted from the cultures by centrifugation at $10,000 \mathrm{rpm}$ for $10 \mathrm{~min}$, resuspended in $300 \mu \mathrm{L}$ of lysis buffer $(10 \mathrm{mM}$ Tris-HCl y $1 \mathrm{mM}$ EDTA, $\mathrm{pH}$ 8.0 , lysozyme $1 \mathrm{mg} / \mathrm{mL}$ ), and incubated at $37^{\circ} \mathrm{C}$ for $0.5 \mathrm{~h}$ or until viscous. DNA from all preparations was subsequently extracted with phenol-chloroform and precipitated with ethanol. DNA samples were dissolved in TE buffer $(10 \mathrm{mM}$ Tris chloride-1 mM EDTA [pH 8.0]).

2.3. Molecular Identification of S. aureus. A final point PCR of the $s p A$ gene was performed to the selected strains for the molecular confirmation of $S$. aureus, with oligonucleotides described in Table 1. The final mixture of each PCR reaction contained $0.2 \mathrm{mM}$ of each dNTP, $3 \mathrm{mM} \mathrm{MgCl}_{2}, 0.2 \mu \mathrm{M}$ of the oligonucleotides, $1 \mathrm{U}$ of Taq DNA polymerase (Ampliqon Cat\# A112103, Denmark), $5 \mu \mathrm{L}$ of 10X Buffer, and $100 \mathrm{ng}$ of DNA as template. The PCR protocol started with an initial denaturation of 5 minutes at $95^{\circ} \mathrm{C}$, followed by 30 cycles at 
TABLE 1: Oligonucleotide primers used for molecular identification, toxin gene detection, and molecular typing.

\begin{tabular}{|c|c|c|c|}
\hline Gene (virulence factor) & Sequence $\left(5^{\prime}-3^{\prime}\right)$ & Size of amplified product (bp) & Reference \\
\hline$s p A($ protein $\mathrm{A})$ & $\begin{array}{l}\text { spaF-CAAGCACCAAAAGAGGAA } \\
\text { spaR-CACCAGGTTTAACGACAT }\end{array}$ & $180-450$ & {$[24]$} \\
\hline coa (coagulase) & $\begin{array}{l}\text { coaF-CGAGACCAAGATTCAACAAG } \\
\text { coaR-AAAGAAAACCACTCACATCA }\end{array}$ & $600-900$ & {$[16]$} \\
\hline $\operatorname{seA}($ enterotoxin $\mathrm{A})$ & $\begin{array}{l}\text { seaF-TGCAGGGAACAGCTTTAGGC } \\
\text { seaR-GTGTACCACCCGCACATTGA }\end{array}$ & 250 & {$[25]$} \\
\hline $\operatorname{seB}($ enterotoxin $\mathrm{B})$ & $\begin{array}{c}\text { sebF-ATTCTATTAAGGACACTAAGTTAGGG } \\
\text { sebR-ATCCCGTTTCATAAGGCGAGT }\end{array}$ & 400 & {$[25]$} \\
\hline $\operatorname{seC}($ enterotoxin $\mathrm{C})$ & $\begin{array}{c}\text { secF-GTAAAGTTACAGGTGGCAAAACTTG } \\
\text { secR-CATATCATACCAAAAAGTATTGCCGT } \\
\text { sedF- }\end{array}$ & 297 & {$[25]$} \\
\hline $\operatorname{seD}($ enterotoxin $\mathrm{D})$ & $\begin{array}{c}\text { GAATTAAGTAGTACCGCGCTAAATAATATG } \\
\text { sedR-GCTGTATTTTTCCTCCGAGAGT }\end{array}$ & 492 & {$[25]$} \\
\hline $\operatorname{seE}($ enterotoxin $\mathrm{E})$ & $\begin{array}{c}\text { seeF-CAAAGAAATGCTTTAAGCAATCTTAGGC } \\
\text { seeR-CACCTTACCGCCCAAAGCTG }\end{array}$ & 480 & {$[25]$} \\
\hline$h l B($ hemolisin $\beta$ ) & $\begin{array}{l}\text { hlbF-GTGCACTTACTGACAATAGTGC } \\
\text { hlbR-GTTGATGAGTAGCTACCTTCAGT }\end{array}$ & 300 & {$[25]$} \\
\hline saK (staphylokinase) & $\begin{array}{c}\text { sakF-ATCCCGTTTCATAAGGCGAGT } \\
\text { sakR-CACCTTACCGCCCAAAGCTG }\end{array}$ & 260 & This work \\
\hline mecA (methicillin resistant) & $\begin{array}{c}\text { mecaF-TCCAGATTACAACTTCACCAGG } \\
\text { mecaR-CCACTTCATATCTTGTAACG }\end{array}$ & 180 & {$[26]$} \\
\hline tsst- 1 (toxic shock syndrome toxin) & $\begin{array}{l}\text { tsstF-CATCTACAAACGATAATATAAAGG } \\
\text { tsstR-CATTGTTATTTTCCAATAACCACCCG }\end{array}$ & 476 & This work \\
\hline
\end{tabular}

$94^{\circ} \mathrm{C}$ for $30 \mathrm{~s}$ at, $52^{\circ} \mathrm{C}$ for $30 \mathrm{~s}$, and $72^{\circ} \mathrm{C}$ for $30 \mathrm{~s}$, and a final elongation at $72^{\circ} \mathrm{C}$ for 5 minutes. The electrophoresis of the obtained PCR products was carried out in $2 \%$ agarose gels at $80 \mathrm{~V}$ for 60 minutes. The gels were stained with Midori Green (Nippon Genetics, Cat\# Mg04, Germany) and visualized with LED light (Nippon Genetics, Germany).

2.4. Identification of Genes Coding for Virulence Factors. Detection of genes $h l B, m e c, s a K, p v L$, tsst-1, seA, seB, seC, $s e D$, and $s e E$ coding for $\beta$-hemolysin, methicillin resistance region, staphylokinase, Panton-Valentine toxin, toxin of the syndrome of the toxic shock, and enterotoxins, respectively, was carried out by PCR in the final point with the oligonucleotides described in Table 1 . The final mixture of each PCR reaction contained $0.2 \mathrm{mM}$ of each $\mathrm{dNTP}, 3 \mathrm{mM}$ $\mathrm{MgCl}_{2}, 0.2 \mu \mathrm{M}$ of the oligonucleotides, $1 \mathrm{U}$ of Taq DNA polymerase (Ampliqon Cat\# A112103, Denmark), $5 \mu \mathrm{L}$ of $10 \mathrm{X}$ Buffer, and $100 \mathrm{ng}$ of DNA as template. In the case of the amplification of the mec gene, a concentration of $\mathrm{MgCl}_{2}$ of $5 \mathrm{mM}$ was used. The reaction mixtures were subjected to the following amplification programs: initial denaturation of 5 minutes at $94^{\circ} \mathrm{C}$, followed by 30 cycles at $94^{\circ} \mathrm{C}$ for $30 \mathrm{~s}$ at, $52^{\circ} \mathrm{C}$ for $30 \mathrm{~s}$ and $72^{\circ} \mathrm{C}$ for $30 \mathrm{~s}$, and a final elongation at $72^{\circ} \mathrm{C}$ for 5 minutes, for the amplification of $m e c, h l B, p v L$, tsst-1, $s e A$, and $s e E$ genes. Initial denaturation of 5 minutes at $94^{\circ} \mathrm{C}$, followed by 30 cycles at $94^{\circ} \mathrm{C}$ for $30 \mathrm{~s}, 52^{\circ} \mathrm{C}$ for $45 \mathrm{~s}$, and $72^{\circ} \mathrm{C}$ for $45 \mathrm{~s}$, and a final elongation at $72^{\circ} \mathrm{C}$ for 5 minutes, for amplification of $s a K, s e B, s e C$, and $s e D$ genes. The electrophoresis of the obtained PCR products was carried out in $2 \%$ agarose gels at $80 \mathrm{~V}$ for 60 minutes. The gels were stained with Midori Green (Nippon Genetics, Cat\# Mg04, Germany) and visualized with LED light (Nippon Genetics, Cat\# Fg05, Germany).
2.5. Expression of $\beta$ Hemolysin. To demonstrate the expression of $\beta$ hemolysin, the strains were cultured by strike on $5 \%$ cell blood agar, incubating at $37^{\circ} \mathrm{C}$ under $\mathrm{CO}_{2}$ tension for $24 \mathrm{~h}$. The strains that presented a halo of transparency in the perimeter of the colonies were considered $\beta$-Hemolytic $(h L B+)$. The strains that presented $\alpha$ - and $\gamma$-hemolysis were considered $h l B-$.

2.6. Antibiotic Susceptibility Tests. An inoculum of each isolated strain equivalent to $0.5 \mathrm{McF}$ arland scale was swabbed onto the Muller Hinton agar plate (BD Bioxon ${ }^{\circledR}$, Cat\# PA-254032.08, Mexico) and the antibiotic disc was then placed on the plate followed by overnight incubation at $37^{\circ} \mathrm{C}$. The inhibition zone was interpreted according to the Clinical Laboratory Standards Institute (CLSI, 2016) [27] guidelines (formerly known as the National Committee for Clinical Laboratory Standards). The tested antibiotics were clindamycin (CC, Oxoid, Cat\# CT0064B, USA) $(2 \mu \mathrm{g})$, cefoxitin (FOX, Oxoid, Cat\# CT0119B, USA) $(30 \mu \mathrm{g})$, rifampicin (RA, Oxoid, Cat\# CT0207B, USA) (5 $\mu \mathrm{g})$, erythromycin (E, Oxoid, Cat\# CT0020B, USA) (15 $\mu \mathrm{g})$, tetracycline (TET, Oxoid, Cat\# CT0054B, USA) $(30 \mu \mathrm{g})$, and ciprofloxacin (CIP, Oxoid, Cat\# CT0425B, USA) (5 $\mu \mathrm{g})$.

2.7. Test for Induction of Clindamycin Resistance. An inoculum of each isolated strain equivalent to $0.5 \mathrm{McF}$ arland scale was swabbed onto the Muller Hinton agar plate (BD Bioxon ${ }^{\circledR}$, Cat\# PA-254032.08, Mexico) and the induction test was performed by manually placing a $2 \mu \mathrm{g}$ clindamycin (CC, Oxoid, Cat\# CT0064B, USA) disk approximately $12 \mathrm{~mm}$ from a $15 \mu \mathrm{g}$ erythromycin (E, Oxoid, Cat\# CT0020B, USA) disk (measured edge to edge). Induction test results were read at 16 to $18 \mathrm{~h}$ using transmitted and reflected light. 
A blunted zone of clindamycin near the erythromycin disk (D-shaped) indicated a phenotype of inducible resistance (inducible MLSB), resistance to erythromycin, and clindamycin indicated a constitutive resistance phenotype (constitutive MLSB) and sensitivity a clindamycin was defined by the absence of induction of clindamycin resistance in the area close to the erythromycin disk [27].

2.8. Molecular Typing of S. aureus. To the molecularly confirmed strains as $S$. aureus, the amplification of the coa gene was performed by PCR in the final point with the oligonucleotides described in Table 1. The final mixture of each PCR reaction contained $0.2 \mathrm{mM}$ of each dNTP, $3 \mathrm{mM}$ $\mathrm{MgCl}_{2}, 0.2 \mu \mathrm{M}$ of the oligonucleotides, $1 \mathrm{U}$ of Taq DNA polymerase (Ampliqon Cat\# A112103, Denmark), $5 \mu \mathrm{L}$ of 10X Buffer, and $100 \mathrm{ng}$ of DNA as template. The PCR protocol started with an initial denaturation of 5 minutes at $94^{\circ} \mathrm{C}$, followed by 30 cycles at $94^{\circ} \mathrm{C}$ for $30 \mathrm{~s}, 52^{\circ} \mathrm{C}$ for $30 \mathrm{~s}$, and $72^{\circ} \mathrm{C}$ for $60 \mathrm{~s}$ and a final elongation at $72^{\circ} \mathrm{C}$ for 5 minutes. PCR product was digested for 2 hours at $37^{\circ} \mathrm{C}$ with $10 \mathrm{U}$ of the restriction endonuclease AluI (Thermo Scientific ${ }^{\circledR}$, Cat\# IVGN0446, EE.UU) according to the manufacturer's recommended protocol [16]. The restriction digest fragments were detected by electrophoresis in $2 \%$ agarose gels at $70 \mathrm{~V}$ for 60 minutes. The gels were stained with Midori Green (Nippon Genetics, Cat\# Mg04, Germany) and visualized with LED light (Nippon Genetics, Germany).

2.9. Statistical Analysis. The statistical package STATA V. 12 (STATA ${ }^{\circledR}$, USA) was used to calculate simple frequencies and the Chi square statistical test was used for possible relationships between the frequencies of virulence and antibiotic resistance genes in relation to the origins of isolation of the strains; values of $p \leq 0.05$ were considered as statistically significant. A logistic regression analysis was performed to estimate differences and a statistically significant relationship among the frequencies of positive strains for $s a K, h l B$, and $s e A$. To compare the frequencies of virulence factors and resistance to antibiotics in MSSA and MRSA strains, Fisher's exact test was used.

The identity coefficient for the PCR-RFLPs technique of the coa gene was calculated with the following equation:

$$
D=1-\frac{1}{N(N-1)} \sum_{j=1}^{S} n_{j}\left(n_{j}-1\right),
$$

where $N$ is the total number of strains in the population of the sample, $s$ is the total number of types described, and $n_{j}$ is the number of strains that belong to the type.

\section{Results and Discussion}

In this study, oligonucleotides directed to the $X$ region of the $s p A$ gene, located between the binding domain membrane and the catalytic portion (binding to FC-IgG) of protein A, were used to determine the species of $S$. aureus polymorphic, by the insertion or depletion of repeated sequences in tandem of $24 \mathrm{bp}$ [28]. Of the 80 selected strains, $80 \%(64 / 80)$ were molecularly confirmed as $S$. aureus from the amplification of the $s p A$ gene. The identified strains were isolated from human nostrils (19/19), milk formula (2/2), and surfaces $(5 / 5)$. The lowest percentage was obtained in vaginal exudate (1/7) (Table 2).

Protein $\mathrm{A}$ is a unique surface protein of the species with evasion functions of the immune system [7]. Other markers used to determine the species were the nuc gene (which codes for the stable thermonuclease) [29] and the region of the 16S rRNA gene [19]. However, the amplification of the $s p A$ gene allows the typing either by a PCR-RFLP technique or sequencing, even from the size of the product generated, indicating differences to rule out clonality of the strains due to the insertion or loss of sequences repeated in tandem in the amplified region. With this technique, $80 \%$ of the strains were molecularly confirmed, making comparison difficult because most of the authors commonly use nuc amplification for identification. However, the nuc gene has been found in other Staphylococcus species, both coagulase positive (S. hyicus, S. delphini, S. intermedius, S. pseudintermedius, and S. schleiferi) and negative (S. capitis, S. caprae, S. epidermidis, S. warneri, S. simulans, S. carnosus, S. kloosii, and S. saprophyticus) [30].

In the strains confirmed as $S$. aureus, the seA gene coding for enterotoxin A was amplified in $53.1 \%$, followed by $t s s t-1$ with $9.3 \%$ and $s e C$ with $6.2 \%$ and with less frequency the $s e D$, $s e B$, and $s e E$ genes with $4.6 \%, 3.1 \%$, and $1.5 \%$, respectively. In the case of other toxins, the staphylokinase gene $(s a K)$ frequency was $57.8 \%$ and that of $\beta$-Hemolysin $(h L B)$ was $17.2 \%$. In the case of resistance to antibiotics, the frequency of the mec gene was $12.5 \%$, classifying the strains as MRSA (Table 3).

Regarding the virulence profiles, the most frequently determined enterotoxin gene was $s e A$, similar to that reported by Bayomi et al. [31] and Hoque et al. [32]. On the other hand, several studies have observed the epidemiological transition and an increase in the frequency of the genes of the $\mathrm{b}(s e B)[11,33], \mathrm{c}(s e C)$ [34], and e (seE) [35] enterotoxins. However, in this study, the frequency of the three was low, considering the frequency of $s e C$, the closest to $s e A$, as reported by Rong et al. [35]. The toxin gene frequency of toxic shock syndrome (tsst-1) was even higher than enterotoxins other than seA. In this sense, an increase in cases of toxic shock syndrome due to $S$. aureus has been reported in relation to those produced by Streptococcus pyogenes [36]. In addition, it is important to note that the higher frequency of $t s s t-1$ in relation to the enterotoxins of $S$. aureus has not been observed in other studies. The highest number of $S$. aureus seA+ strains was found in the food group (18/34). In the case of positive strains to the other enterotoxins ( $s e B, s e C, s e D$, and $s e E$ ) were found only in the human group. In this study, the most frequent virulence factor gene was $s a K(57.8 \%)$, with a higher number of strains carrying this gene in the human group $(p=0.001)$.

It is important to demonstrate the circulation of enterotoxigenic strains in multiple environments, due to the role they play; in food, the production of enterotoxins is associated with the development of food poisoning [2]; in humans, if they prepare food, they could transfer it to them, 
TABLE 2: Source of isolation and molecular confirmation of strains of S. aureus used in the study.

\begin{tabular}{lcc}
\hline Source & S. aureus sub-aureus & \\
\hline Animals & & \\
$\quad$ Bovine mastitis & & 4 \\
\hline Humans & & \\
$\quad$ Vagina & 7 & 1 \\
Nostrils* & 19 & 19 \\
Nasopharynx & 8 & 8 \\
Hands & 9 & 5 \\
\hline Foods & & 15 \\
Cheeses & 7 & 6 \\
Eggshell & 2 & 2 \\
Food infant & 5 & 5 \\
Surfaces & 5 & \\
\hline
\end{tabular}

${ }^{8}$ Samples were obtained by swabbing or exudate. ${ }^{*}$ Previously isolated on [20]. ${ }^{\$}$ Previously isolated on [19].

TABLE 3: Virulence factors of strains of S. aureus from different environments.

\begin{tabular}{|c|c|c|c|c|c|}
\hline Virulence factor & Total $N=64 n(\%)$ & Humans $N=33$ & Foods $N=27$ & Animals $N=4$ & $p^{+}$ \\
\hline \multicolumn{6}{|l|}{ Enterotoxins* } \\
\hline seA & $34(53.1)$ & 16 & 16 & 2 & 0.702 \\
\hline$s e B$ & $2(3.1)$ & 2 & 0 & 0 & 0.379 \\
\hline$s e C$ & $4(6.2)$ & 4 & 0 & 0 & 0.135 \\
\hline$s e D$ & $3(4.6)$ & 3 & 0 & 0 & 0.228 \\
\hline$s e E$ & $1(1.5)$ & 1 & 0 & 0 & 0.621 \\
\hline tsst -1 & $6(9.3)$ & 3 & 3 & 0 & 0.774 \\
\hline Toxins* & & & & 0 & \\
\hline$h l B$ & $11(17.2)$ & 2 & 7 & 2 & 0.025 \\
\hline$s a K$ & $37(57.8)$ & 27 & 8 & 2 & 0.000 \\
\hline \multicolumn{6}{|l|}{ Antibiotic resistance } \\
\hline mec & $8(12.5)$ & 4 & 4 & 0 & 0.702 \\
\hline
\end{tabular}

${ }^{*}$ Determined by end point PCR. ${ }^{+}$Determined by Fisher's exact test and square Chi. Values of $p<0.05$ were considered statistically significant and are marked in table.

highlighting the importance of nasal carriers in the epidemiology of the microorganism [22, 31], while in animals, such as cows, enterotoxigenic strains can be transferred from bovine udders by dragging and contaminating milk, the raw material for multiple foods of dairy origin [37].

In addition to the enterotoxins, the genes coding for $\beta$-hemolysin $(h l B)$ and staphylokinase $(s a K)$ was searched, which, in addition to contributing to virulence, have been described as mutually exclusive. The bacteriophage $(\beta \mathrm{C}-\varphi s)$ that contains the sak and seA genes generates non- $\beta$-hemolytic $(h l B-)$ strains when inserted into the $h l B$ gene [38]. Therefore, in this study, in addition to determining the presence of the $h l B$ gene, the functionality of $\beta$-hemolysin was proved, for the oligonucleotides are not designed to determine the truncated or complete form of the gene. Therefore, the $\beta$-hemolysis in sheep blood was determined in the $h l B+$ strains, finding a statistically significant relationship between the nonhemolytic strains and the presence of the $s e A$ and $s a K$ genes, determining that they have a high probability of carrying the $s e A$ gene $(p=0.056)$ and the $s a K$ gene $(p=0.024)$ but not necessarily both genes $(p=0.739)$. In addition, it has been described that the $s e A$ and sak genes are part of the cluster of evasion of the immune system together with the hol, lytA, chp, and scn genes [38], so it is proposed that, in the $s e A-s a K$ strains from this study, the search for cluster genes is associated with immune evasion. When demonstrating the expression of the $h l B$ gene, it was found that only $17.18 \%(11 / 64)$ of the strains were $\beta$-hemolytic and $82.81 \%(53 / 64)$ were $\alpha$ - or $\gamma$-hemolytic. In addition, it was determined if there was a statistical relationship between $\beta$ - and $\gamma$-hemolytic strains with the frequency of the $s a K$ and seA genes, finding a high frequency of positive strains for the $s a K(p=0.056)$ and $\operatorname{seA}(p=0.024)$ genes in the group of nonhemolytic strains $(h l B-)$ (Table 4$)$.

The profiles of antimicrobial resistance showed that the strains from food showed greater resistance to erythromycin (40.7\%) and ciprofloxacin (18.5\%) followed by tetracycline and clindamycin (14.8\% and $11.1 \%$, respectively); the lowest frequency was observed in rifampicin (3.7\%). In strains of S. aureus from humans, a greater resistance was observed to erythromycin (48.4\%), followed by clindamycin (21.2\%) and rifampicin (12.1\%). A lower resistance was observed to tetracycline (12.2\%) and ciprofloxacin $(9.1 \%)$. Resistance to cefoxitin in both groups was similar (14.8\% and $12.1 \%$ in food and humans, respectively). Strains from animals showed greater resistance to erythromycin (75\%); this is 
TABle 4: Frequency of the $s a K$ and $s e A$ genes in beta (hlb+) and gamma (hlb-) hemolytic $S$. aureus strains.

\begin{tabular}{lccc}
\hline \multirow{2}{*}{ Virulence factor } & \multicolumn{3}{c}{$h l b$} \\
& Positives $n=11$ & Negatives $n=53$ & $p$ \\
\hline seA & $3(27.27)$ & $31(58.49)$ & 0.056 \\
saK & $3(27.27)$ & $34(64.15)$ & 0.024 \\
\hline
\end{tabular}

Values of $p<0.05$ were considered as statistically significant and are marked in the table. The statistical analysis was performed with Fisher's exact test.

even greater than the other two study groups; no MRSA was found in these strains (Figure 1).

When observing a high resistance to erythromycin, the inducible clindamycin effect was found with a frequency of $1.56 \%$, which corresponds to a strain isolated from the nasal (human) nostrils. Regarding resistance to antibiotics of $S$. aureus, a greater resistance to erythromycin and clindamycin was found in humans. This trend has been reported in clinical isolation [39-41], hands of food handlers [31, 42], and in foods such as chicken [31], fish, and shrimp [35]. As for tetracycline, the frequency of resistant strains was low in both groups, which is contrary to that described by Mekonnen et al. [43] and Asiimwe et al. [34]. This could be explained for the isolates came from animals (cattle) and milk; in this study, there were only 4 strains from cow udders. The frequency of MRSA in this study per group was $14.8 \%$ and $12.1 \%$ for food and humans, respectively, which is similar to that reported in the hands of chicken handlers $(10 \%)$, chicken $(8 \%)$ [31], ready-to-eat food rich in starch (8\%) [33], shrimp, and fish (8\%) [35]. The highest frequencies are usually from hospital isolates ranging from 35 to $81.4 \%[11,40,41]$, justifying that in the study the isolates of $S$. aureus were not of hospital origin.

The study of antimicrobial resistance in S. aureus has different approaches; in the medical and veterinary area, it is related to therapeutic failure to resolve infections by this microorganism $[14,44]$. In the area of food, its participation in the resolution of food poisoning is still under discussion, because it is related to the presence of toxins and not the microorganism, but it has raised food as a vehicle for the transmission of resistant strains [45], which occurs and has been evidenced between animals and humans $[46,47]$. In addition, it is important to evaluate resistance profiles, since they change between geographical areas, types of food, and the origin of the strain (whether community or hospital), as observed in what was previously described.

Of the 64 strains confirmed by $s p A$, it was possible to typify $68.7 \%$ of the strains (45/64) by PCR-RFLP of the coa gene, finding 17 restriction profiles (restriction) based on the restriction products generated by the AluI enzyme, commonly determined from 2 to 3 fragments of different molecular weight. The product of amplification of the coa gene without any cut (profile 1) was considered as a restriction. The most common restriction profile was 4 ( $490 \mathrm{bp}, 300 \mathrm{bp}$ ) grouping 7 strains, followed by profiles 2 ( $400 \mathrm{bp}, 300 \mathrm{bp}$ ) and $8(500 \mathrm{bp}, 320 \mathrm{bp}$, and $180 \mathrm{bp})$ with 5 strains each. According to the origin of the strains, profiles 1 and 2 were only determined in strains of human origin, 14 in strains of animal origin, and profiles $3,5,8,10,11,12,15$, and 17 only

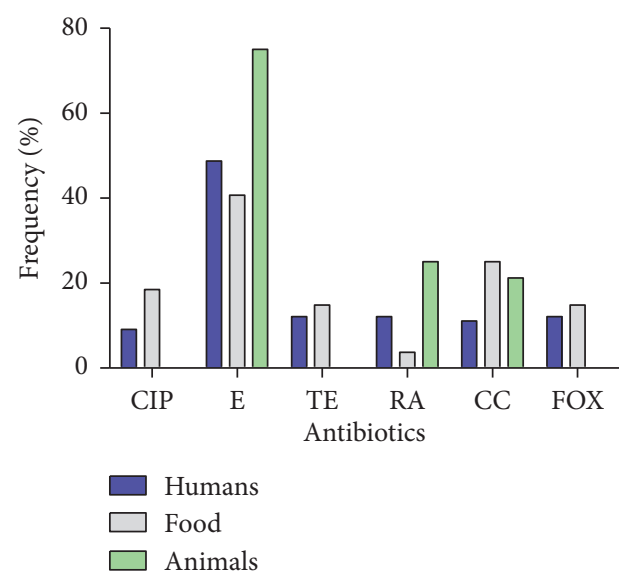

FIgURE 1: Antibiotic resistance in S. aureus strains from humans, food, and animals.

in strains isolated from food. Profiles 4, 6, 7, 13, and 16 in strains were isolated from both humans and food (Table 5).

A method for the typing of $S$. aureus is the PCR-RFLP technique of the gene that codes for coagulase (coa). This enzyme has the function of generating fibrin clots and, thus, participates in the evasion and invasion of the microorganism in the host [7]. The gene is divided into three regions: one cell membrane binding, one polymorphic, and one fibrinogen binding. In the polymorphic region, there may be insertion or loss of tandem repeats of $81 \mathrm{bp}$. The latter allows typifying the strains, generating different sizes of gene amplification and, therefore, the restriction of the same [16]. The percentages of typing of this gene range from 40 to $100 \%$ $[16,19,28,43,48-53]$. These typing rates are related to the years in which the isolations were taken, where the percentage is lower (40 and 51\%) in studies conducted in recent years $[19,29,54]$ compared to those made in the previous two decades, where the percentage was $100 \%[16,49-53]$. This may be due to the evolution of the strains and the incorporation of mutations in the 3' region of the gene, decreasing the specificity of the used primers, highlighting that the primers described by Goh et al. [16] were used in this study. Another important point is that the study only considered the strains with the amplification of a single product and not the allelic forms, as reported in other studies $[16,19,48,53]$. The restriction products were generated in this study ranged from $80 \mathrm{bp}$ to $500 \mathrm{bp}$, which is consistent with has been previously reported [16, 19, 48-53]. It was also considered as a different profile to the PCR product, where there was no cut by the enzyme restriction AluI, which was also included in several studies [50-52]. We obtained 17 restriction profiles of 45 unrelated strains, which is similar to that reported by Schwarkopf and Karch [46, 53]; the number of profiles decreases when the strains are isolated from the same origin or environment $[29,54]$ or have a common characteristic, for example, being MRSA $[16,52]$. The diversity of these could be explained by the evolution and adaptation of $S$. aureus to different environments, geographic zones, and even hosts [51]. Even when the number of restrictions is diverse, in most of these studies, one of 
TABLE 5: Restriction profiles of the coa gene, virulence factors, and resistance profile of strains of $S$. aureus from different environments.

\begin{tabular}{|c|c|c|c|c|c|}
\hline Profile & AluI restriction & Strains & Virulence factor (gen) & Resistance profile & Source \\
\hline 1 & 800 & 4 & $\begin{array}{c}h l B, \operatorname{saK}(1) \\
h l B, \operatorname{seA}, \operatorname{seC}(1) \\
\text { saK (1) } \\
\text { saK, mec, seA (1) }\end{array}$ & $\begin{array}{c}\text { Cc (1) } \\
\text { Susceptible (2) } \\
\text { Fox, E (1) }\end{array}$ & Humans \\
\hline 2 & 400300 & 5 & $\begin{array}{c}s a K, \operatorname{seA}(1) \\
s a K(2) \\
h l B, s e A, s e C(1) \\
h l B, s a K, \operatorname{seA}(1)\end{array}$ & $\begin{array}{c}\text { Cip, E (2) } \\
\text { Susceptible (3) }\end{array}$ & Humans \\
\hline 3 & 40015080 & 1 & $h l B$, saK, seA, tsst-1 (1) & Susceptible (1) & Foods \\
\hline 4 & 490300 & 7 & $\begin{array}{c}s a K, s e B(1) \\
s a K, s e A, s e C(1) \\
h l B, s a K, s e B, s e C, s e D(1) \\
h l B(1) \\
h l B, s a K(1) \\
s a K(1) \\
s a K, \text { mec, seA (1) }\end{array}$ & $\begin{array}{c}\text { E (2) } \\
\text { Cc (1) } \\
\text { Cc, E, Ra (1) } \\
\text { Cip, E (1) } \\
\text { Fox (1) } \\
\text { Susceptible (1) }\end{array}$ & Foods/humans \\
\hline 5 & 450220 & 2 & mec, seA (1) & $\begin{array}{c}\text { Fox (1) } \\
\text { Susceptible (1) }\end{array}$ & Foods \\
\hline 6 & 400220 & 3 & $\begin{array}{c}s a K(1) \\
h l B, s a K, \text { seA (1) } \\
\text { saK, seA, seE, tsst-1 (1) }\end{array}$ & $\begin{array}{c}\text { Cc, E (1) } \\
\text { Te, Cip, E (1) } \\
\text { Susceptible (1) }\end{array}$ & Foods/humans \\
\hline 7 & 500220 & 2 & $\begin{array}{c}\text { hlB, saK (1) } \\
h l B(1) \\
\end{array}$ & Susceptible (2) & Foods/humans \\
\hline 8 & 500320180 & 5 & $\begin{array}{c}h l B, \operatorname{se} A(3) \\
h l B(1) \\
---\end{array}$ & $\begin{array}{c}\text { Te (1) } \\
\text { E (1) } \\
\text { Susceptible (3) } \\
\end{array}$ & Foods \\
\hline 9 & 550400180 & 1 & $s a K, m e c, s e A(1)$ & Fox, E (1) & Humans \\
\hline 10 & 40023080 & 1 & $h l B, s a K, s e A(1)$ & $\mathrm{E}(1)$ & Foods \\
\hline 11 & 50032080 & 1 & $h l B(1)$ & $\mathrm{E}(1)$ & Foods \\
\hline 12 & 40018080 & 1 & $s a K$, tsst-1 (1) & Susceptible (1) & Foods \\
\hline 13 & 400200 & 4 & $\begin{array}{c}h l B, \text { saK, seA (1) } \\
\text { saK, seA (1) } \\
\text { saK, seA, tsst }-1 \text { (1) } \\
\text { saK, mec (1) }\end{array}$ & $\begin{array}{c}\text { E (2) } \\
\text { Fox, E, Ra (1) } \\
\text { Susceptible (1) }\end{array}$ & Foods/humans \\
\hline 14 & 400290180 & 1 & $h l B, s a K, s e A(1)$ & $\mathrm{E}(1)$ & Animals \\
\hline 15 & 40032080 & 2 & $\begin{array}{l}s a K(1) \\
h l B(1)\end{array}$ & Susceptible (2) & Foods \\
\hline 16 & 400320 & 3 & $\begin{array}{c}\operatorname{seA}(1) \\
h l B, \operatorname{se} A(1) \\
---\end{array}$ & $\begin{array}{c}\text { Te (1) } \\
\text { Susceptible (1) } \\
\text { E (1) }\end{array}$ & Foods/humans \\
\hline 17 & 490210 & 2 & $\begin{array}{c}s a K(1) \\
h l B, \text { mec, seA (1) }\end{array}$ & $\begin{array}{c}\text { E (1) } \\
\text { Fox, Cip, E (1) }\end{array}$ & Foods \\
\hline
\end{tabular}

these restrictions is always the most common, which can be related as the restriction best adapted to the geographical area [29] and even to the guests of the same area; in this sense, it has been described that the restrictotypes, the most common of the studied region, present a greater resistance to opsonization by neutrophils than the less common restrictions [51]. By relating the virulence factors with the restriction profiles, it was found that profile 4 had strains with a higher number of enterotoxin genes. In profiles 7,11 , and 15, strains did not present enterotoxin genes, while in profiles $3,6,12$, and 13 , strains presented the tsst-1 gene. In profile 5 , there were no strains with the $h l B$ or $s a K$ genes. In profile 4 , strains resistant to cefoxitin, clindamycin, ciprofloxacin, erythromycin, and rifampin were found. Also, in profiles $1,4,5,9,13$, and 17 , there were strains resistant to cefoxitin. In this study, the most common restriction was 4 (490 bp-300 bp) and it had the most virulence factors, such as $s e A, s e B, s e C, s e D, h l B, s a K$, and $m e c$, with strains resistant to all antibiotics, except tetracycline, and of combined origin between humans and food, which are associated with a greater adaptation of the strains due to the greater acquisition of virulence factors. 
TABLE 6: Virulence factors and antibiotic resistance in MSSA and MRSA strains.

\begin{tabular}{lccc}
\hline & MSSA & MRSA & $p^{*}$ \\
\hline Virulence factor & & & \\
$0-2$ virulence genes & $47(83.9)$ & $3(37.5)$ & $\mathbf{0 . 0 0 3}$ \\
$\geq 3$ virulence genes & $9(16)$ & $5(62.5)$ & \\
\hline Antibiotics & & & \\
Clindamycin & $9(16)$ & $2(25)$ & 0.617 \\
Ciprofloxacin & $5(8.9)$ & $3(37.5)$ & 0.054 \\
Erythromycin & $24(42.9)$ & $6(75)$ & 0.133 \\
Rifampicin & $5(8.9)$ & $1(12.5)$ & 0.567 \\
Tetracycline & $6(10.7)$ & $2(25)$ & 0.260 \\
\hline
\end{tabular}

${ }^{*}$ Calculated from Fisher's exact test. MSSA, Staphylococcus aureus sensitive to methicillin. MRSA, Staphylococcus aureus resistant to methicillin. Values of $p<0.05$ were considered statistically significant and are marked in the table.

The PCR-RFLP technique of the coa gene could be complemented with the amplification data of the spA gene; however, it was determined that the power of discrimination of the technique was 0.93 , considered within the acceptance range (above 0.8 ). In other studies in which this technique has been used, the power of reported discrimination was $0.81,0.99$, and 0.80 , the first two with strains isolated from milk of cattle with mastitis $[48,49]$ and the last one of bovine milk [19]. It has been reported that by combining two techniques, for example, PCR-RFLPs of the coa gene with ribotyping, the discrimination power is increased from 0.81 to 0.89 [49]; however, in this study, the power of unmatched discrimination was still above that reported. This confirms that the technique of the coa gene is easy and reproducible and that it can be used for the typing of strains from different environments.

By grouping the strains according to methicillin resistance, it was observed that strains containing 0 to 2 virulence genes were more frequent in the group of methicillin-sensitive S. aureus (MSSA) (83.9\%) compared to methicillinresistant S. aureus group (MRSA) (37.5\%). Strains carrying 3 or more virulence genes were more frequent with $62.5 \%$ in the MRSA group compared to the MSSA with $16 \%$ $(p=0.003)$. Regarding antibiotic resistance, in the MRSA strains, the antibiotics to which resistance was the highest were erythromycin and ciprofloxacin, with $75 \%$ and $37.5 \%$ $(p=0.054)$, respectively, while in the MSSA strains, the antibiotics to which there was higher resistance were erythromycin and clindamycin, with $42.9 \%$ and $10 \%$ correspondingly (Table 6).

\section{Conclusions}

In this study, a wide genetic diversity of strains of $S$. aureus from different foods, humans, and animals was found, evidenced by the restriction of the polymorphic region of the gene coding for coagulase, as well as virulence and resistance profiles obtained by PCR at the endpoint and by the Kirby Bauer method, respectively. This demonstrates evolution, genetic versatility, and, therefore, the adaptation of this microorganism in different environments. Remark the importance of its study in different dietary matrices as contaminant and pathogen in animals and humans, as part of the microbiota of the skin and mucous membranes or pathogen in these same sites.

\section{Data Availability}

The data used in the study are available on request.

\section{Conflicts of Interest}

The authors declare that there are no conflicts of interest regarding the publication of this paper.

\section{Acknowledgments}

This work was supported by the Secretaria de Educación Publica. Roberto Adame Gomez had a student scholarship [829282] granted by Consejo Nacional de Ciencia y Tecnología.

\section{References}

[1] S. Y. C. Tong, J. S. Davis, E. Eichenberger, T. L. Holland, and V. G. Fowler Jr., "Staphylococcus aureus infections: epidemiology, pathophysiology, clinical manifestations, and management," Clinical Microbiology Reviews, vol. 28, no. 3, pp. 603-661, 2015.

[2] J.-A. Hennekinne, M.-L. D. Buyser, and S. Dragacci, "Staphylococcus aureus and its food poisoning toxins: characterization and outbreak investigation," FEMS Microbiology Reviews, vol. 36, no. 4, pp. 815-836, 2012.

[3] J. Schelin, N. Wallin-Carlquist, M. T. Cohn, R. Lindqvist, and G. C. Barker, "The formation of Staphylococcus aureus enterotoxin in food environments and advances in risk assessment," Virulence, vol. 2, no. 6, pp. 580-592, 2011.

[4] J. Kadariya, T. C. Smith, and D. Thapaliya, "Staphylococcus aureus and staphylococcal food-borne disease: an ongoing challenge in public health," Biomed Research International, vol. 2014, Article ID 827965, 9 pages, 2014.

[5] M.-L. D. Buyser, B. Dufour, M. Maire, and V. Lafarge, "Implication of milk and milk products in food-borne diseases in France and in different industrialised countries," International Journal of Food Microbiology, vol. 67, no. 1-2, pp. 1-17, 2001.

[6] D. Balasubramanian, L. Harper, B. Shopsin, and V. J. Torres, "Staphylococcus aureus pathogenesis in diverse host environments," Pathogens and Disease, vol. 75, 2017.

[7] M. Dominique and S. Olaf, "Staphylococcus aureus vaccines: deviating from the carol," Journal of Experimental Medicine, vol. 213, no. 9, pp. 1645-1653, 2016.

[8] C. Kong, H.-M. Neoh, and S. Nathan, "Targeting Staphylococcus aureus toxins: a potential form of anti-virulence therapy," Toxins, vol. 8, no. 3, p. E72, 2016.

[9] W. V. Schaik and T. Abee, "The role of $\sigma \mathrm{B}$ in the stress response of gram-positive bacteria-targets for food preservation and safety," Current Opinion in Biotechnology, vol. 16, no. 2, pp. 218-224, 2005.

[10] N. Malachowa and F. R. DeLeo, "Mobile genetic elements of Staphylococcus aureus," Cellular and Molecular Life Sciences, vol. 67, no. 18, pp. 3057-3071, 2010.

[11] C. He, S. Xu, H. Zhao et al., "Leukotoxin and pyrogenic toxin Superantigen gene backgrounds in bloodstream and wound 
Staphylococcus aureus isolates from eastern region of China," BMC Infectious Diseases, vol. 18, no. 1, p. 395, 2018.

[12] R. P. Novick, G. E. Christie, and J. R. Penadés, "The phagerelated chromosomal islands of gram-positive bacteria," Nature Reviews Microbiology, vol. 8, no. 8, pp. 541-551, 2010.

[13] A. K. Shamila-Syuhada, G. Rusul, W. A. Wan-Nadiah, and L. O. Chuah, "Prevalence and antibiotics resistance of Staphylococcus aureus isolates isolated from raw milk obtained from small-scale dairy farms in penang, Malaysia," Pakistan Veterinary Journal, vol. 36, pp. 98-102, 2016.

[14] S. Khanam, J. A. Haq, S. Shamsuzzaman, M. M Rahman, and K. Z. Mamun, "Emergence of vancomycin resistant Staphylococcus aureus during hospital admission at a tertiary care hospital in Bangladesh," Bangladesh Journal of Infectious Diseases, vol. 3, no. 1, pp. 11-16, 2016.

[15] R. H. Deurenberg, C. Vink, S. Kalenic, A. W. Friedrich, C. A. Bruggeman, and E. E. Stobberingh, "The molecular evolution of methicillin-resistant Staphylococcus aureus," Clinical Microbiology and Infection, vol. 13, no. 3, pp. 222-235, 2007.

[16] S. H. Goh, S. K. Byrne, J. L. Zhang, and A. W. Chow, "Molecular typing of Staphylococcus aureus on the basis of coagulase gene polymorphisms," Journal of Clinical Microbiology, vol. 30, no. 7, pp. 1642-1645, 1992.

[17] F. C. Tenover, R. Arbeit, G. Archer et al., "Comparison of traditional and molecular methods of typing isolates of Staphylococcus aureus," Journal of Clinical Microbiology, vol. 32, no. 2, pp. 407-415, 1994.

[18] A. Vindel, O. Cuevas, E. Cercenado et al., "Spanish group for the study of Staphylococcus. Methicillin-resistant Staphylococcus aureus in Spain: molecular epidemiology and utility of different typing methods," Journal of Clinical Microbiology, vol. 47, no. 6, pp. 1620-1627, 2009.

[19] V. Sharma, S. Sharma, D. K. Dahiya, A. Khan, M. Mathur, and A. Sharma, "Coagulase gene polymorphism, enterotoxigenecity, biofilm production, and antibiotic resistance in Staphylococcus aureus isolated from bovine raw milk in North West India," Annals of Clinical Microbiology and Antimicrobials, vol. 16, no. 1, p. 65, 2017.

[20] A. Salehzadeh, H. Zamani, M. K. Langeroudi, and A. Mirzaie, "Molecular typing of nosocomial Staphylococcus aureus strains associated to biofilm based on the coagulase and protein A gene polymorphisms," Iranian Journal of Basic Medical Sciences, vol. 19, pp. 1325-1330, 2016.

[21] R. Adame-Gómez, J. Toribio-Jimenez, A. Vences-Velazquez et al., "Methicillin-resistant Staphylococcus aureus (MRSA) in artisanal cheeses in méxico," International Journal of Microbiology, vol. 2018, no. 6, Article ID 8760357, 2018.

[22] R. Adame-Gómez, A. Vences-Velázquez, I. Parra-Rojas, E. Rodríguez-Bataz, S. Muñoz-Barrios, and A. RamírezPeralta, "Staphylococcus aureus resistentes a meticilina (SARM) y productores de enterotoxina a aislados de portadores nasales asintomáticos entre estudiantes universitarios de México," Kasmera, vol. 47, pp. 14-20, 2019.

[23] J. B. D. S. Rodrigues, T. S. Pinto, C. P. D. Oliveira et al., "Lipolytic activity of Staphylococcus aureus from human wounds, animals, foods, and food-contact surfaces in Brazil," The Journal of Infection in Developing Countries, vol. 8, no. 8, pp. 1055-1058, 2014.

[24] C. Lange, M. Cardoso, D. Senczek, and S. Schwarz, "Molecular subtyping of Staphylococcus aureus isolates from cases of bovine mastitis in Brazil," Veterinary Microbiology, vol. 67, no. 2, pp. 127-141, 1999.

[25] S. Jarraud, C. Mougel, J. Thioulouse et al., "Relationships between Staphylococcus aureus genetic background, virulence factors, agr groups (alleles), and human disease," Infection and Immunity, vol. 70, no. 2, pp. 631-641, 2002.

[26] C. Milheiriço, D. C. Oliveira, and H. D. Lencastre, "Update to the multiplex PCR strategy for assignment of mec element types in Staphylococcus aureus," Antimicrobial Agents and Chemotherapy, vol. 51, no. 12, p. 4537, 2007.

[27] Clinical Laboratory Standards Institute, Performance Standards for Antimicrobial Susceptibility Testing, 26th Informational Supplement (M100-S16), CLSI, Wayne, PA, USA, 2016.

[28] H. M. Frénay, J. P. Theelen, L. M. Schouls et al., "Discrimination of epidemic and nonepidemic methicillin-resistant Staphylococcus aureus strains on the basis of protein A gene polymorphism," Journal of Clinical Microbiology, vol. 32, no. 3, pp. 846-847, 1994.

[29] F. Javid, A. Taku, M. A. Bhat, G. A. Badroo, M. Mudasir, and T. A. Sofi, "Molecular typing of Staphylococcus aureus based on coagulase gene," Veterinary World, vol. 11, no. 4, pp. 423-430, 2018.

[30] S. Hirotaki, T. Sasaki, K. Kuwahara-Arai, and K. Hiramatsu, "Rapid and accurate identification of human-associated staphylococci by use of multiplex PCR," Journal of Clinical Microbiology, vol. 49, no. 10, pp. 3627-3631, 2011.

[31] R. M. E. Bayomi, H. A. Ahmed, M. A. I. Awadallah, R. A. Mohsen, A. E. A. El-Ghafar, and M. A. Abdelrahman, "Occurrence, virulence factors, antimicrobial resistance, and genotyping of Staphylococcus aureus strains isolated from chicken products and humans," Vector-Borne and Zoonotic Diseases, vol. 16, no. 3, pp. 157-164, 2016.

[32] M. N. Hoque, Z. C. Das, A. N. M. A. Rahman, M. G. Haider, and M. A. I. Islam, "Molecular characterization of Staphylococcus aureus strains in bovine mastitis milk in Bangladesh," International Journal of Veterinary Science and Medicine, vol. 6, no. 1, pp. 53-60, 2018.

[33] X. Yang, S. Yu, Q. Wu, J. Zhang, S. Wu, and D. Rong, "Multilocus sequence typing and virulence-associated gene profile Analysis of Staphylococcus aureus isolates from retail ready-to-eat food in China," Frontiers in Microbiology, vol. 9, p. 197, 2018.

[34] B. B. Asiimwe, R. Baldan, A. Trovato, and D. M. Cirillo, "Prevalence and molecular characteristics of Staphylococcus aureus, including methicillin resistant strains, isolated from bulk can milk and raw milk products in pastoral communities of South-West Uganda," BMC Infectious Diseases, vol. 17, no. 1, p. 422, 2017.

[35] D. Rong, Q. Wu, M. Xu, J. Zhang, and S. Yu, "Prevalence, virulence genes, antimicrobial susceptibility, and genetic diversity of Staphylococcus aureus from retail aquatic products in China," Frontiers in Microbiology, vol. 8, p. 714, 2017.

[36] M. A. Smit, A.-C. Nyquist, and J. K. Todd, "Infectious shock and toxic shock síndrome diagnoses in hospitals, Colorado, USA," Emerging Infectious Diseases, vol. 19, no. 11, pp. 1855-1858, 2013.

[37] R. Piccinini, L. Cesaris, V. Daprà et al., "The role of teat skin contamination in the epidemiology of Staphylococcus aureus intramammary infections," The Journal of Dairy Research, vol. 76, no. 1, pp. 36-41, 2009.

[38] W. J. V. Wamel, S. H. Rooijakkers, M. Ruyken, K. P. V. Kessel, and J. A. V. Strijp, "The innate immune modulators staphylococcal complement inhibitor and chemotaxis inhibitory protein of Staphylococcus aureus are located on beta-hemolysin-converting bacteriophages," Journal of Bacteriology, vol. 188, no. 4, pp. 1310-1315, 2006.

[39] S. Ansari, R. Gautam, S. Shrestha, S. R. Ansari, S. N. Subedi, and M. R. Chhetri, "Risk factors assessment for nasal 
colonization of Staphylococcus aureus and its methicillin resistant strains among pre-clinical medical students of Nepal," BMC Research Notes, vol. 9, no. 1, 2016.

[40] S. Manandhar, A. Singh, A. Varma, S. Pandey, and N. Shrivastava, "Biofilm producing clinical Staphylococcus aureus isolates augmented prevalence of antibiotic resistant cases in tertiary care hospitals of Nepal," Frontiers in Microbiology, vol. 9, p. 2749, 2018.

[41] B. Liang, J. Mai, Y. Liu et al., "Prevalence and characterization of Staphylococcus aureus isolated from women and children in guangzhou, China," Frontiers in Microbiology, vol. 9, p. 2790, 2018.

[42] A. Castro, C. Santos, H. Meireles, J. Silva, and P. Teixeira, "Food handlers as potential sources of dissemination of virulent strains of Staphylococcus aureus in the community," Journal of Infection and Public Health, vol. 9, no. 2, pp. 153-160, 2016.

[43] S. A. Mekonnen, T. J. G. M. Lam, J. Hoekstra et al., "Characterization of Staphylococcus aureus isolated from milk samples of dairy cows in small holder farms of North-Western Ethiopia," BMC Veterinary Research, vol. 14, no. 1, p. 246, 2018.

[44] V. Peton and Y. L. Loir, "Staphylococcus aureus in veterinary medicine," Infection, Genetics and Evolution, vol. 21, pp. 602-615, 2014.

[45] D. Sergelidis and A. S. Angelidis, "Methicillin-resistant Staphylococcus aureus: a controversial food-borne pathogen," Letters in Applied Microbiology, vol. 64, no. 6, pp. 409-418, 2017.

[46] N. Balaban and A. Rasooly, "Staphylococcal enterotoxins," International Journal of Food Microbiology, vol. 61, no. 1, pp. 1-10, 2000.

[47] A. L. Honeyman, Staphylococcus aureus Infection and Disease, Kluwer Academic/Plenum Publishers, New York, NY, USA, 2001.

[48] E. R. D. Silva and N. D. Silva, "Coagulase gene typing of Staphylococcus aureus isolated from cows with mastitis in southeastern Brazil," Canadian Journal of Veterinary Research, vol. 69, pp. 260-264, 2005.

[49] F. M. Aarestrup, C. A. Dangler, and L. M. Sordillo, "Prevalence of coagulase gene polymorphism in Staphylococcus aureus isolates causing bovine mastitis," Canadian Journal of Veterinary Research, vol. 59, pp. 124-128, 1995.

[50] J. Schlegelová, M. Dendis, J. Benedík, V. Babák, and D. Rysánek, "Staphylococcus aureus isolates from dairy cows and humans on a farm differ in coagulase genotype," Veterinary Microbiology, vol. 92, no. 4, pp. 327-334, 2003.

[51] C. Su, C. Herbelin, N. Frieze, O. Skardova, and L. M. Sordillo, "Coagulase gene polymorphism of Staphylococcus aureus isolates from dairy cattle in different geographical áreas," Epidemiology and Infection, vol. 122, no. 2, pp. 329-336, 1999.

[52] J. V. Hookey, J. F. Richardson, and B. D. Cookson, "Molecular typing of Staphylococcus aureus based on PCR restriction fragment length polymorphism and DNA sequence analysis of the coagulase gene," Journal of Clinical Microbiology, vol. 36, no. 4, pp. 1083-1089, 1998.

[53] A. Schwarzkopf and H. Karch, "Genetic variation in Staphylococcus aureus coagulase genes: potential and limits for use as epidemiological marker," Journal of Clinical Microbiology, vol. 32, no. 10, pp. 2407-2412, 1994.

[54] H. Momtaz, E. Tajbakhsh, E. Rahimi, and M. Momeni, "Coagulase gene polymorphism of Staphylococcus aureus isolated from clinical and sub-clinical bovine mastitis in Isfahan and Chaharmahal va Bakhtiari provinces of Iran," Comparative Clinical Pathology, vol. 20, no. 5, pp. 519-522, 2011. 